\title{
Longitudinal Study on the Impact of Three Major Regulations on the Korean Pharmaceutical Industry in the Last 30 Years
}

Seung In Um

KPBMA

\section{Uy Dong Sohn}

Chung-Ang University

\section{Sun-Young Jung}

Chung-Ang University

\section{Seung-Hun You}

Chung-Ang University

Changone Kim

Keimyung University

\section{Sora Lee}

Sungkyunkwan University

Heesang Lee ( $\nabla$ leehee@skku.edu )

Sungkyunkwan University https://orcid.org/0000-0002-2796-6126

\section{Research}

Keywords: Pharmaceutical industry, innovation, regulations, patent, GMP, drug pricing system

Posted Date: April 12th, 2021

DOl: https://doi.org/10.21203/rs.3.rs-391717/v1

License: (9) (i) This work is licensed under a Creative Commons Attribution 4.0 International License. Read Full License

Version of Record: A version of this preprint was published at Health Research Policy and Systems on January 6th, 2022. See the published version at https://doi.org/10.1186/s12961-021-00797-9. 


\section{Longitudinal Study on the Impact of Three Major Regulations on the Korean Pharmaceutical Industry in the Last 30 Years}

Seung In Um ${ }^{1}$, Uy Dong Sohn ${ }^{2}$, Sun-Young Jung ${ }^{3}$, Seung-Hun You ${ }^{4}$, Changone Kim ${ }^{5}$, Sora Lee ${ }^{6}$, Heesang Lee ${ }^{6 *}$

\footnotetext{
1 Korea Pharmaceutical and Bio-Pharma Manufacturers Association

2 Department of Pharmacology, Chung-Ang University

3 College of Pharmacy, Chung-Ang University

4 Department of Global Innovative Drugs, Chung- Ang University

5 Graduate School of Global Entrepreneurship, Keimyung University

${ }^{6}$ Graduate School of Management of Technology, Sungkyunkwan University

* Correspondence: leehee@skku.edu
} 
3 Background: The pharmaceutical industry is heavily regulated. Partly for this reason, new

4 drugs generally take over ten years to reach market entry from the product development stage.

5 Although regulations affect the pharmaceutical industry over a long time, extant studies have

6 usually focused on the short period before and after implementing a new regulatory policy to

7 determine the impact of that policy. The purpose of this study is to examine whether and how

8 significant regulatory policies affect long-term innovation in the pharmaceutical industry in

9 Korea.

10 Methods: This study focused on three significant regulatory policies: the product patent 11 system, changes in the Good Manufacturing Practice (GMP) system, and the Drug Expenditure Rationalization Plan (DERP). This study used Interrupted Time Series (ITS) analysis to investigate the policies' long-term impacts before and after their implementation.

Results: Our results show that the introduction of the product patent system in 1987 significantly increased the number of Korean patent applications. The revised GMP policies' effect was also statistically significant, both before and after implementation and between preemptive companies and non-preemptive ones. The DERP, however, did not significantly delay new drug registration in Korea due to companies' negotiations with the regulatory authorities or the system that links drug approval and price evaluation.

Conclusion: This study showed that the policies of the product patent system, GMP policies, and DERP regulations have significantly altered the course of the pharmaceutical industry in Korea. This study suggests that it is necessary for companies to preemptively respond to systemic changes in development and production strategies to deal with regulatory changes and achieve sustainable growth. Also, this study implies that the governmental authorities 
25 need to develop a regulatory policy that links innovation and competitiveness in domestic 26 pharmaceutical companies.

27 Keywords: Pharmaceutical industry, innovation, regulations, patent, GMP, drug pricing 28 system 


\section{Introduction}

2 The pharmaceutical industry develops new drugs to address unmet medical needs and extend

3 lifespan [1]. Simultaneously, it contributes significantly to a country's economy and promotes

4 GDP growth due to knowledge-based technological innovation [2]. The pharmaceutical

5 industry is a more high-technology, high-growth, and knowledge-based sector than most

6 other industrial sectors. New drug development generally takes over $10-15$ years, and each

7 new drug has a low probability of success [3,4]. Recently, the average overall cost of

8 developing a new drug was estimated at US\$ 2.8 billion [5]. One reason for the high R\&D

9 costs is the tight and inflexible nature of pharmaceutical regulations [6]. For example, smaller

10 U.S. pharmaceutical firms suffered devastating reductions in research productivity because of

11 FDA regulations [7]. In addition, clinical trials, which account for the most significant proportion of total R\&D time due to strong safety and effectiveness regulations, have recently become more complex and costly [3].

Regulations are necessary to ensure pharmaceutical safety and effectiveness as well as the accuracy of the information given to customers and are linked to manufacturers' market responsibilities [8]. Pharmaceutical regulations have different goals depending on the income

17 level of the applicable country. Generally, low-income countries value the quality of medicines, middle-income countries value fiscal and industrial development, and highincome countries value innovation in new drug $R \& D$ [9]. There are many pharmaceutical regulations, but some of the most critical regulatory policies that impact pharmaceutical innovation concern the patent system, GMP, and price controls [10-15]. A new innovative drug, the final output of innovation by the pharmaceutical industry, must be approved by the regulatory authorities at every development stage. Suppose a drug that is not validated for 
safety or efficacy is released without approval by a regulatory authority, or a marketed drug is not controlled because of ineffective regulations. It will almost certainly be a disaster [16, 17]. The pharmaceutical industry, which is based on regulation, grows through innovation. Therefore, it is necessary to analyze any changes in a country's regulatory policies and the long-term impact of such policy changes on innovation and growth in the pharmaceutical industry. This study investigates the long-term effects of three significant changes in pharmaceutical regulations over the last 30 years in Korea, where the pharmaceutical industry expanded by about eight-fold between 1988 and 2017. The first significant change is the introduction of the product patent system in 1987; the second is the changes to the GMP system in 1994, 2008, and 2014; and the final one is the DERP, the new pharmaco-economic evaluation system, in 2006. We used the following three research questions to analyze the impacts of these three regulatory changes.

Research Question 1. Did the introduction of the product patent system increase the number of patent applications filed by the pharmaceutical industry in Korea?

Research Question 2. Did companies that preemptively invested in GMP facilities before mandatory GMP maintain sustainable growth in Korea?

Research Question 3. Did the DERP delay the introduction of new drugs in Korea?

\section{Product patent regulation and pharmaceutical innovation}

The role of patents is to encourage innovation in biopharmaceuticals and accelerate the development of new drugs. The introduction and strengthening of the product patent system have shifted the pharmaceutical industry from imitation to innovation [18]. Prior research shows a positive correlation among product patents, new drugs, and $\mathrm{R} \& \mathrm{D}[10,19,20]$. The 
patent system in the United States provides an incentive for R\&D by protecting the exclusive right to recover profit for a considerable period [21]. The Indian pharmaceutical industry grew tenfold between introducing the patent laws in 1970 and the early 2000s [21].

Korea first enacted the Patent Law in 1946, then joined the Paris Convention in 1980 and the Patent Cooperation Treaty (PCT) in 1982. The Korean government revised the Patent Law to reflect the product patent system on Dec 29, 1986. Subsequently, the domestic pharmaceutical industry's technological innovation was promoted by the revised laws in 1990 and 2001 [22]. Several studies have shown that Korean patent applications have continued to increase in number since the 1980s [23, 24], and the number of Korean patent applications has surpassed that of foreign applications since 1992 [24].

Though many studies have analyzed the impact of changes in the Korean patent system, most such studies investigated the effects of introducing a new patent system on the pharmaceutical industry by focusing on the short period before and after the new system's introduction. Lee (2002) and Yoon (2004) revealed an increase in the number of pharmaceutical patent applications by conducting trend analysis of descriptive statistics [23, 24].

As the first research question, we ask whether there were any changes in the number of Korean patent applications filed by the pharmaceutical industry over the 18-year from 1981 to 1998 , which encompasses the introduction of the product patent system in Korea in 1987. An increase in the number of patent applications under the new product patent system would be a cornerstone for long-term innovation in the Korean pharmaceutical industry.

\section{GMP regulations and the sustainable growth of pharmaceutical companies}

GMP refers to regulations, codes, and guidelines for manufacturing final pharmaceutical 페이지 6 / 28 
products, raw materials, medical devices, and diagnostic products. Pharmaceutical companies worldwide must apply GMP to all manufacturing and quality control processes [17]. GMP regulation has resulted in smaller companies giving up on new drug innovation and instead focusing on me-too drug development. However, large companies create new drugs by steadily investing in R\&D and manufacture the drugs following GMP regulations.

In Korea, like in the United States, Europe, and Japan, the GMP system has been continuously strengthened and revised through international harmonization [25]. Korea established GMP standards in 1977, which were autonomous regulations at that time. The Korean government implemented mandated GMP production facilities for pharmaceutical manufacturers in 1994 and introduced a new GMP system requiring validation in 2008. Later, in 2014, the Korean GMP system joined the Pharmaceutical Inspection Co-operation Scheme (PIC/s), and GMP in Korea was internationalized. It has been steadily revised in concert with WHO and global standards [26]. Some studies have examined the GMP system changes by period and compared them among different countries [12, 25, 26]. As the second research question, this study determines whether there was a difference in growth according to pharmaceutical companies' readiness for each change in regulations due to a change in Korean GMP policy.

\section{Price regulations and the introduction of new drugs}

Previous studies have demonstrated that price regulation negatively affects the timing and occurrence of the launch of a new drug [11]. Most drug price controls significantly impact pharmaceutical companies' innovation strategies and financial status by reducing the companies' revenue and investment in R\&D through phenomena known as the cash-flow effect and the expected-profit effect [13, 27]. 
Korea's National Health Insurance (NHI) system implemented a reimbursement reform through the DERP in 2006. At that time, the NHI was running a cumulative financial deficit due to high expenditure on drugs with a fast growth rate. The DERP aims to reduce the health insurance budget. The main contents of the DERP implemented in December 2006 were the introduction of a positive drug listing system, a requirement for submission of pharmacoeconomic evaluation data for new drug listings, and changes in the pricing policy for generic drugs. Insurance registration of a new drug became more complicated due to the requirement for submission of economic evaluation data and negotiation with the regulatory authority. The registration period was extended after the change in the drug pricing system following the introduction of the DERP [28].

Son (2018) investigated the effect of new drug registration on licensing and insurance registration from 2007 to 2016 in Korea [29]. According to the study, the duration between regulatory approval and the reimbursement decision decreased. Various stakeholders in the market adopt a new drug insurance listing, considering their strategic behavior, and have different listing periods due to diverse factors [29]. As the third research question, this study tries to determine how the new drug reimbursement registration period changed before and after implementing the DERP system.

\section{Methods}

\section{Data}

This study retrieved patent application data from 1981 to 2016 from the Korea Intellectual Property Rights Information Service (KIPRIS) to address Research Question 1. We selected the international patent classification (IPC) codes A61K (Preparations for medical, dental, or toilet purposes) and C07 (Organic chemistry) by the year of the filing date. We excluded IPC 
codes A61K 6 (Dental-related product) and A61K 7 (Cosmetics), as well as the codes related to health foods.

For Research Question 2, we first obtained a list of the companies that preemptively prepared for the GMP changes from 1985 to 1990, before implementation of the mandatory GMP system, from the book, "The History of Korea Pharmaceutical Manufacturers Association (KPMA)'s 50 years" [30]. Sixteen foreign pharmaceutical factories and 34 domestic companies were recorded in this book. In this study, we included only domestic companies. Among the 34 domestic manufacturers, we excluded one company that went through a merger and two companies that do not currently produce pharmaceuticals. The total production of the 31 companies accounted for $49.3 \%$ of all Korean pharmaceutical production at that time, and 20 out of the 31 companies were in the top 30 pharmaceutical companies in Korea in 1994 . We assessed the production quantity of each pharmaceutical company from 1988 to 2017 for Research Question 2. We classified these 31 companies as group 1, the preemptively prepared for GMP regulations group, while the remaining 230 companies were classified as group 2. Group 2 acquired GMP certificates only after the GMP regulations became mandatory in 1994 . We then analyzed the effects of three changes in GMP regulations (in 1994, 2008, and 2014).

We investigated the date of new drug approval by the Ministry of Food and Drug Safety and the start date of health insurance application coverage for Research Question 3 using the Health Insurance Review \& Assessment Service (HIRA) database. A total of 780 new drugs were approved from 1989 to 2017, and we counted different ingredients on the Active Pharmaceutical Ingredient (API) list for each drug as separate items. Among the 780 new drugs, those not covered by health insurance, such as Over the Counter (OTC) drugs and vaccines, were excluded from the analysis. We calculated the number of months between a 
product's approval date and the application date of health insurance coverage. If the approval date was later than or the same as the commencement date of insurance benefits due to M\&A or changes in import permits and manufacturing permits, we excluded that case. Finally, we selected 620 new drugs and calculated the period from new drug approval to insurance registration.

\section{ITS Analysis - Methodology}

ITS analysis is a quasi-experimental design that uses segmented regression modeling. Since ITS allows longitudinal data to evaluate intervention effects, it is an appropriate statistical method for observing changes before and after implementing an intervention, such as a government regulation [31]. ITS analysis can demonstrate an intervention effect by statistically measuring outcome variables at different time points before and after an intervention to compare the change in the level and trend of the outcomes [32]. In ITS, a time series is an iterative observation of a particular event collected at regular time intervals divided into two or more segments at change points [33]. Two parameters, level and trend, identify each element of the time series. The level and trend indicate the series value at the beginning of a given time interval and the rate of change during a segment, respectively [33, 34].

Based on the literature, ITS analysis for a single intervention without a comparison group, called the single-intervention one-group model, can be explained as follows [31, 34, 35]. There are three variables for an ITS analysis in a single-intervention one-group model:

i. $T$ : the time elapsed since the start of the study,

ii. $X_{t}$ : a dummy variable representing the intervention (the pre-intervention period takes 
a value of 0 , while the post-intervention period takes a value of 1 ),

iii. $Y_{t}$ : the outcome at time t.

This ITS model has three measures of interest: the pre-intervention trend, the postintervention trend, and the difference between the pre-intervention and post-intervention trends.

$$
Y_{t}=\beta_{0}+\beta_{1} T+\beta_{2} X_{t}+\beta_{3} T X_{t}+e_{t}
$$

where $\beta_{0}$ indicates the baseline level at $T=0, \beta_{1}$ is the trend of the outcome variable until indicates the random variability that is not explained by the model. the beginning of the intervention, $\beta_{2}$ indicates the change in the level following the intervention, and $\beta_{3}$ represents the change in the trend following the intervention. In this model, $\beta_{1}+\beta_{3}$ represents the post-intervention trend and $e_{t}$, the error term at time $t$,

\section{Results}

Research Question 1: Did the introduction of the product patent system increase the number of patent applications filed by the pharmaceutical industry in Korea?

For ITS analysis of pharmaceutical patents, as the output variable, we counted the number of patent applications filed per quarter from 1981 to 1998 . We used ITS analysis with a singleintervention one-group model to analyze the effects of implementing the product patent system, with July 1987 as the intervention time.

$$
Y_{t}=\beta_{0}+\beta_{1} T+\beta_{2} X_{t}+\beta_{3} T X_{t}+e_{t}
$$

The calendar year: January of 1981 - December of 1998.

$T$ : the time elapsed since January 1981 
$191 X_{t}$ : a dummy variable indicating before (coded 0) and after (coded 1) enforcement of the 192 product patent system in July 1987

193 Count: No. of patent applications per quarter

$194 \beta_{0}$ : the baseline level in January 1981

$195 \beta_{1}$ : the underlying trend before the introduction of the product patent system

$196 \beta_{2}$ : the level change after the introduction of the product patent system

$197 \beta_{3}$ : the slope change after the introduction of the product patent system

$198 \beta_{1}+\beta_{3}:$ the slope after the introduction of the product patent system

199

200 The results of ITS analysis show that $\beta_{0}=12.2314, \beta_{1}=3.5109, \beta_{2}=95.6962$, and $201 \beta_{3}=3.9667$. The $\mathrm{p}$-values of $\beta_{1}, \beta_{2}$, and $\beta_{3}$ were $0.00,0.01$, and 0.01 , respectively, all of 202 which are less than the significance level of 0.05 (Fig. 1, Table 1). There was a level shift 203 after the intervention $\left(\mathrm{p}<0.05\right.$ for $\left.\beta_{2}\right)$ as well as a trend change after the intervention $(\mathrm{p}<$ 204 0.05 for $\beta_{3}$ ) (Table 1$)$ 


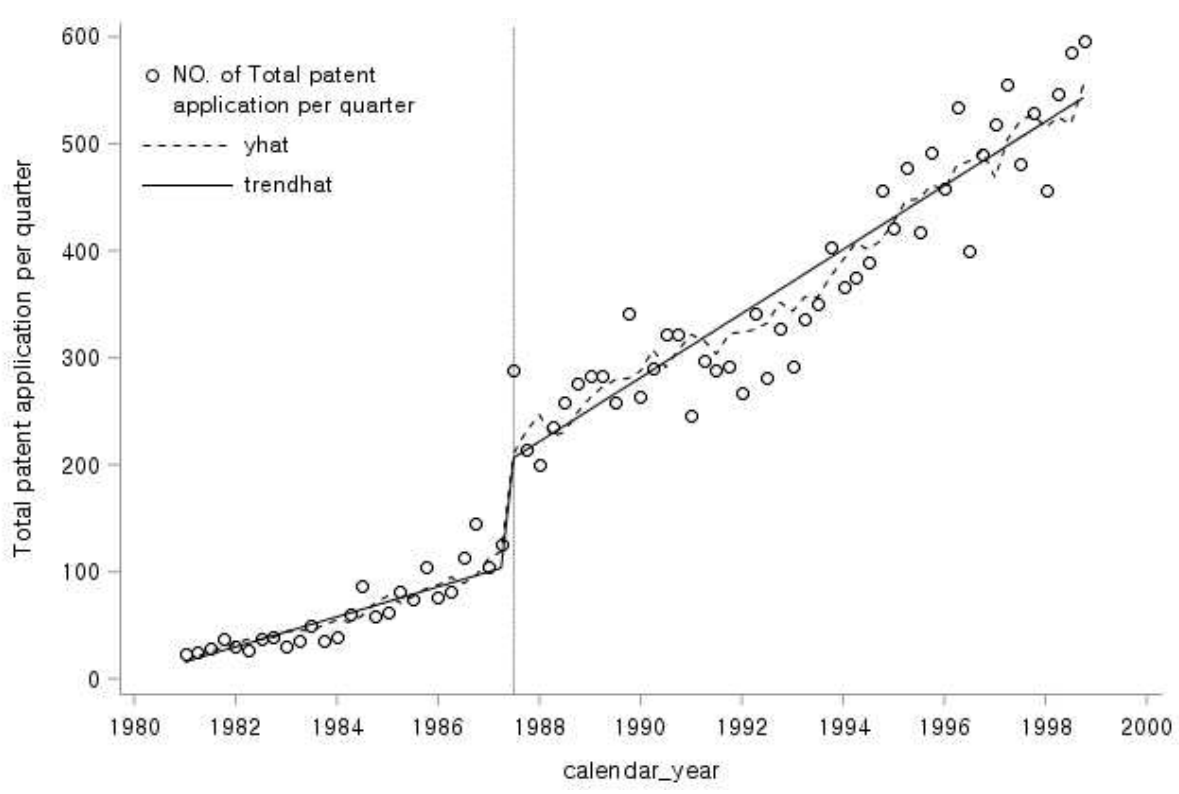

Fig. 1 The graphical results of ITS analysis of the total number of patent applications

Table 1 The statistical results of ITS analysis of the total number of patent applications

\begin{tabular}{lrrrc}
\hline \multicolumn{1}{c}{ Variable } & Coefficient & \multicolumn{1}{c}{ S.E. } & \multicolumn{1}{c}{$t$} & $\boldsymbol{p}$ \\
\hline Intercept $\beta_{0}$ & 12.23 & 21.28 & 0.57 & 0.57 \\
Baseline trend $\beta_{1}$ & 3.51 & 23.22 & 4.12 & 0.00 \\
Level change after policy $\beta_{2}$ & 95.70 & 1.32 & 2.65 & 0.01 \\
Trend change after policy $\beta_{3}$ & 3.97 & 1.52 & 2.61 & 0.01 \\
\end{tabular}

To compare the effects of introducing the product patent system between Korean and foreign companies, we divide the total patent applications into Korean patent applications and foreign patent applications. The number of patents filed by Koreans increased after 211 introducing the product patent system, with a change in slope (Fig. 2). ITS analysis indicated 212 that $\beta_{0}=1.7675, \beta_{1}=0.3087, \beta_{2}=-8.6469$, and $\beta_{3}=2.8654$. The $\mathrm{p}$-values for $\beta_{1}$ and $\beta_{2}$ were 0.3693 and 0.5732 , respectively, which were greater than 0.05 and were thus not 214 statistically significant (Table 2). However, the regression coefficient $\beta_{3}$ was significant, 

significantly affected the trend in Korean patent applications.

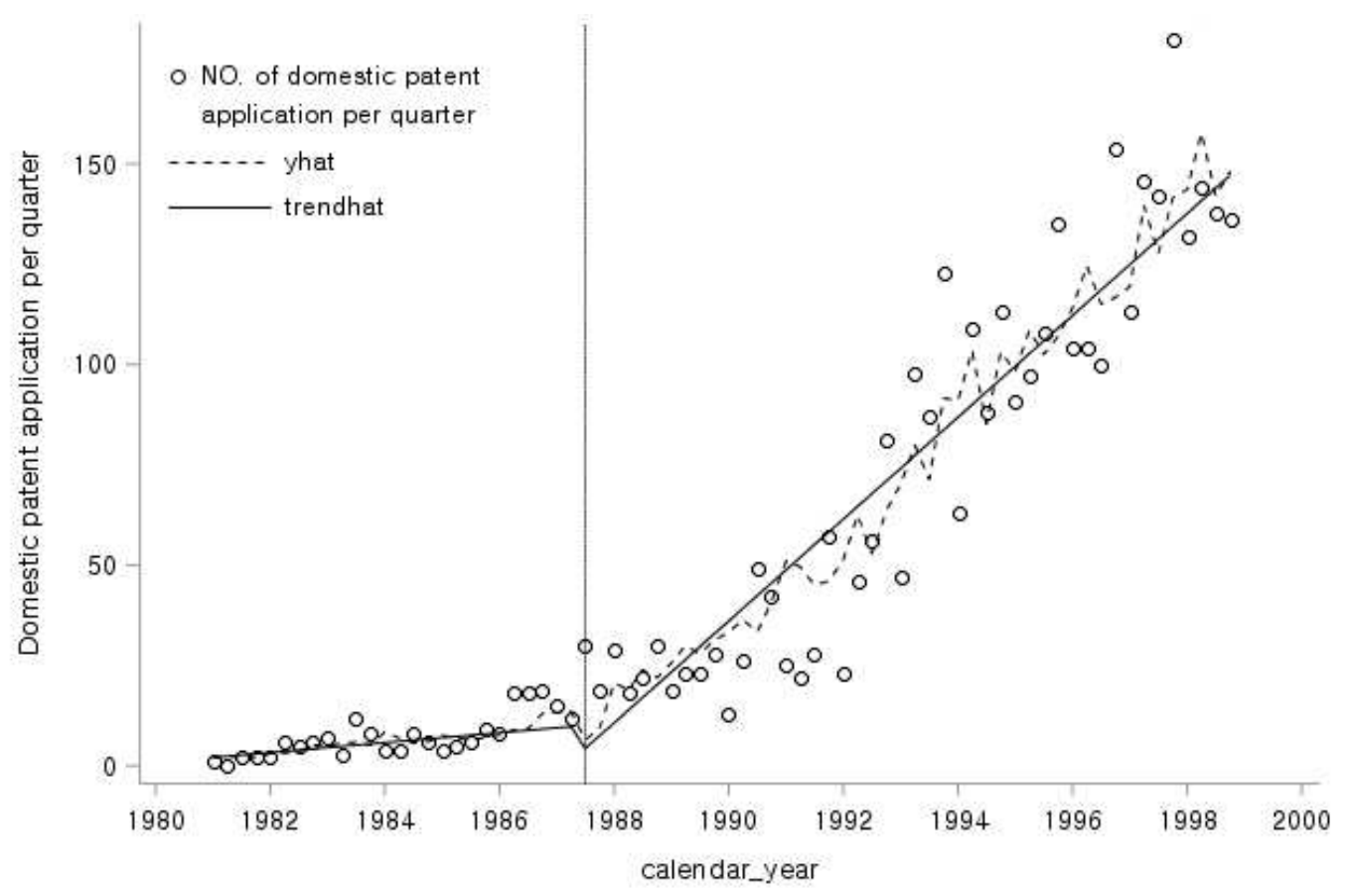

Fig. 2 The graphical results of ITS analysis on the total number of Korean patent applications

218 Table 2 The statistical results of ITS analysis on the total number of Korean patent applications

\begin{tabular}{lcccc}
\hline \multicolumn{1}{c}{ Variable } & Coefficient & S.E. & $\boldsymbol{t}$ & $\boldsymbol{p}$ \\
\hline Intercept $\beta_{0}$ & 1.7675 & 8.7580 & 0.02 & 0.8407 \\
Baseline trend $\beta_{1}$ & 0.3087 & 9.5650 & -0.90 & 0.3693 \\
Level change after policy $\beta_{2}$ & -8.6469 & 0.5452 & 0.57 & 0.5732 \\
Trend change after policy $\beta_{3}$ & 2.8654 & 0.6265 & 4.57 & $<.0001$ \\
\hline
\end{tabular}

221 the intervention (Fig. 3). As shown in Table 3, $\beta_{0}=8.9220, \beta_{1}=3.3391, \beta_{2}=103.3646$, and $\beta_{3}=0.8637$. The regression coefficients of $\beta_{1}$ and $\beta_{2}$ were statistically significant, 
223 with $\mathrm{p}$-values of less than 0.05 . The $\mathrm{p}$-value for $\beta_{3}$ was 0.4914 , which is greater than the 224 significance level of 0.05 , so $\beta_{3}$ was not significant (Table 3). A rapid increase in foreign 225 patents' level followed the introduction of the product patent system, but the trend was not 226 statistically significant.

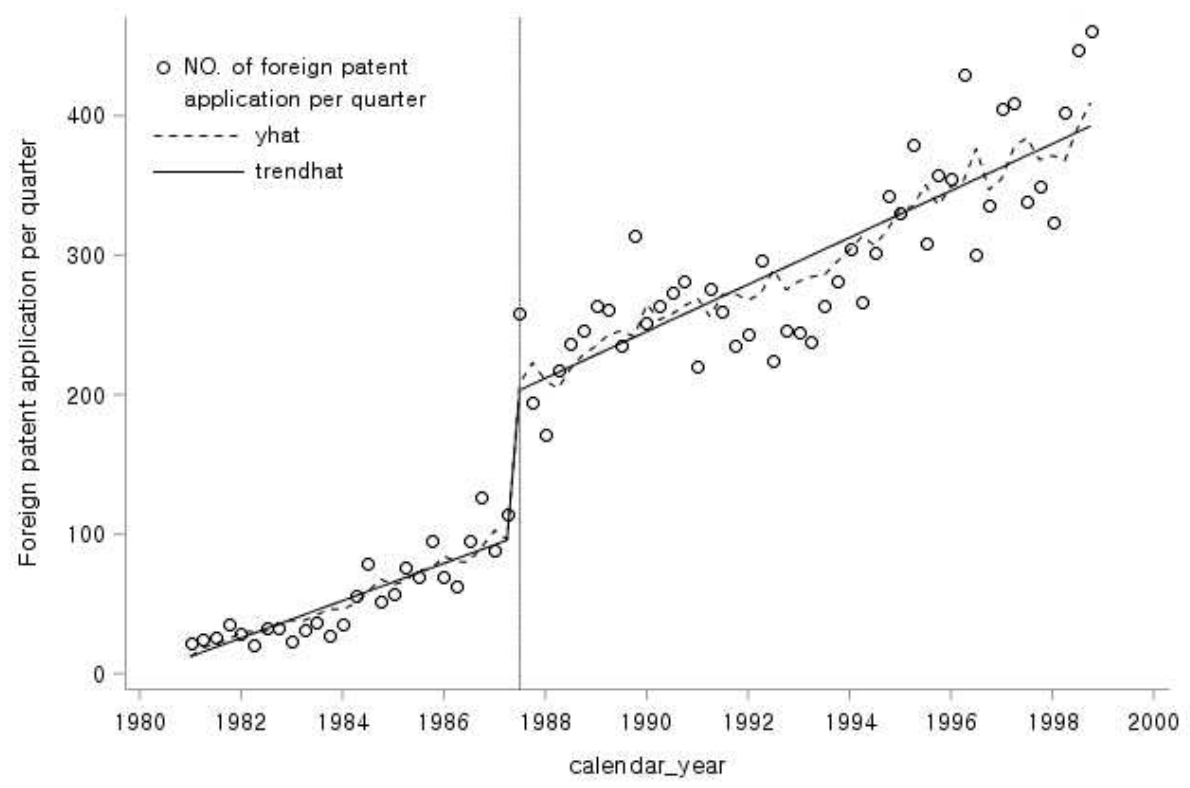

Fig. 3 The graphical results of ITS analysis on the total number of foreign patent applications

Table 3 The statistical results of ITS analysis on the total number of foreign patent applications

\begin{tabular}{lrrrr}
\hline \multicolumn{1}{c}{ Variable } & Coefficient & \multicolumn{1}{c}{ S.E. } & \multicolumn{1}{c}{$\boldsymbol{T}$} & \multicolumn{1}{c}{$\boldsymbol{p}$} \\
\hline Intercept $\beta_{0}$ & 8.9220 & 17.5990 & 0.51 & 0.6139 \\
Baseline trend $\beta_{1}$ & 3.3391 & 20.4569 & 5.05 & $<.0001$ \\
Level change after policy $\beta_{2}$ & 103.3646 & 1.1236 & 2.97 & 0.0041 \\
Trend change after policy $\beta_{3}$ & 0.8637 & 1.2481 & 0.69 & 0.4914
\end{tabular}


total patent applications and a more positive effect in the trend change of Korean patent applications.

Research Question 2: Did companies that preemptively invested in GMP facilities before mandatory GMP maintain sustainable growth in Korea?

There were several changes in the GMP policy in Korea: Mandatory implementation of GMP in 1994, pre-approval GMP evaluation for manufacturing items in 2008, harmonization with the PIC/s GMP Guides in 2014, and periodic GMP evaluation carried out on the dosage forms of all manufacturing sites.

Thirty-one companies preemptively invested and became GMP-certified from 1985 to 1990 before GMP was legally mandated. These preemptively prepared companies (Group 1) had a total production value of 138 trillion won over 30 years and an average annual growth rate of $6.9 \%$ over 30 years. The non-preemptively prepared companies (Group 2) had a total production value of 135 trillion won and growth rates as high as $8.4 \%$ (Table 4). In terms of production performance, companies that preemptively invested before mandatory GMP implementation in 1994 predominated the initial market. In 2008, when the capital investment was required due to the mandatory GMP validation, the 31 preemptively prepared companies increased their output further. In 2014, the PIC/s GMP system did not require capital investment, so the system's impact was negligible. Instead, it was estimated to have a reversal effect due to the price slashing of finished drugs in 2012.

The changes in production before and after the three most significant changes in GMP regulations are shown in Fig. 4. 
Table 4 Total production of Group 1 and Group 2 companies

\begin{tabular}{cccccccc}
\hline & \multicolumn{7}{c}{ Production amount (Bill. W) } \\
\cline { 2 - 7 } Group 1 & Total & $\mathbf{1 9 8 9} \mathbf{1 9 9 3}$ & $\mathbf{1 9 9 4 ~ 1 9 9 8}$ & $\mathbf{2 0 0 3 ~ 2 0 0 7}$ & $\mathbf{2 0 0 8} \mathbf{2 0 1 2}$ & $\mathbf{2 0 1 0 ~ 2 0 1 3}$ & $\mathbf{2 0 1 4} \mathbf{2 0 1 7}$ \\
\hline \multirow{2}{*}{ Group 2 } & 134,022 & 9,578 & 15,582 & 24,561 & 35,537 & 28,620 & 29,983 \\
& & & & & & & \\
Difference & 3,118 & 1,042 & 224 & 223 & 3,742 & 1,414 & $-2,533$ \\
& $(2.3 \%)$ & $(12.2 \%)$ & $(1.5 \%)$ & $(0.9 \%)$ & $(11.8 \%)$ & $(5.2 \%)$ & $(-7.8 \%)$ \\
\hline
\end{tabular}

256

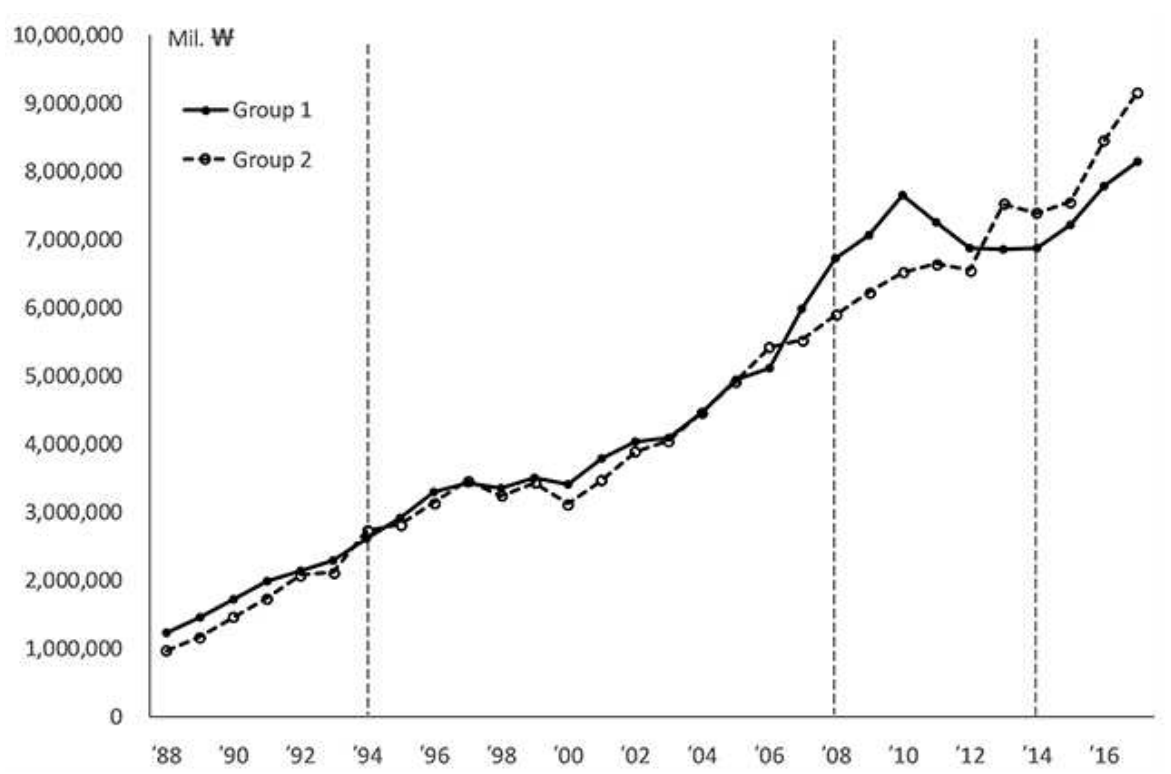

Fig. 4 Total production by Group 1 and Group 2 companies over time

We used ITS analysis again to see if preemptive investments in GMP facilities affected

Korean pharmaceutical companies' sustainable growth. Since this ITS analysis has three interventions and two groups, Group 1 with preemptive investments in GMP facilities and Group2 without preemptive investments, we need to extend the single-intervention one-group model of section 2 to a model with multiple interventions and a comparison group [34, 35]. represents the mandatory GMP policy in 1994, Policy 2 represents the requirement for pre- 
approval for GMP evaluation of manufacturing items in 2008, and Policy 3 represents PIC/s

GMP in 2014. The final ITS model with three interventions and a comparison group was as follows.

$Y_{t}=\beta_{0}+\beta_{1} T+\beta_{2} X_{1 t}+\beta_{3} T_{1 t} X_{1 t}+\beta_{4} X_{2 t}+\beta_{6} X_{3 t}+\beta_{7} T_{3 t} X_{3 t}+\beta_{8} Z+\beta_{9} Z T+$ $\beta_{10} Z X_{1 t}+\beta_{11} Z T_{1 t} X_{1 t}+\beta_{12} Z X_{2 t}+\beta_{13} Z T_{2 t} X_{2 t}+\beta_{14} Z X_{3 t}+\beta_{15} Z T_{3 t} X_{3 t}+e_{t}$,

where $X_{1 t}, T_{1 t} X_{1 t}, Z X_{1 t}$, and $Z T_{1 t} X_{1 t}$ represent the Policy 1 period. $X_{2 t}, T_{2 t} X_{2 t}, Z X_{2 t}$, and $Z T_{2 t} X_{2 t}$ represent the Policy 2 period, and $X_{3 t}, T_{3 t} X_{3 t}, Z X_{3 t}$, and $Z T_{3 t} X_{3 t}$ reflect the Policy 3 period. $Z$ is a dummy variable denoting the cohort assignment (preemptive investments in GMP facilities or not), and $Z T, Z X_{1 t}, Z T_{1 t} X_{1 t}, Z X_{2 t}, Z T_{2 t} X_{2 t}, Z X_{3 t}$, and $Z T_{3 t} X_{3 t}$ are all interaction terms among previously described variables. The coefficients $\beta_{0}$ to $\beta_{7}$ represent the levels or trends of the control group (non-preemptive investments in GMP facilities), and the coefficients $\beta_{8}$ to $\beta_{15}$ represent the levels or trends of the treatment group (preemptive investments in GMP facilities).

Policy 2, and Policy 3 trends for the treatment group and the control group; the differences between groups in their trends in each of these periods, the differences between each period's trends for the treatment group and control group (preintervention versus Policy 1, preintervention versus Policy 2, preintervention versus Policy 3, Policy 1 versus Policy 2, Policy 1 versus Policy 3, and Policy 2 versus Policy 3), and the contrast between groups for each of these periodic comparisons. The regression output provides these eight measures: $\beta_{1}$, 287 $\beta_{3}, \beta_{5}, \beta_{7}, \beta_{9}, \beta_{11}, \beta_{13}$, and $\beta_{15}$. The remaining 22 composite measures of interest can be 

of the GMP policy.

290

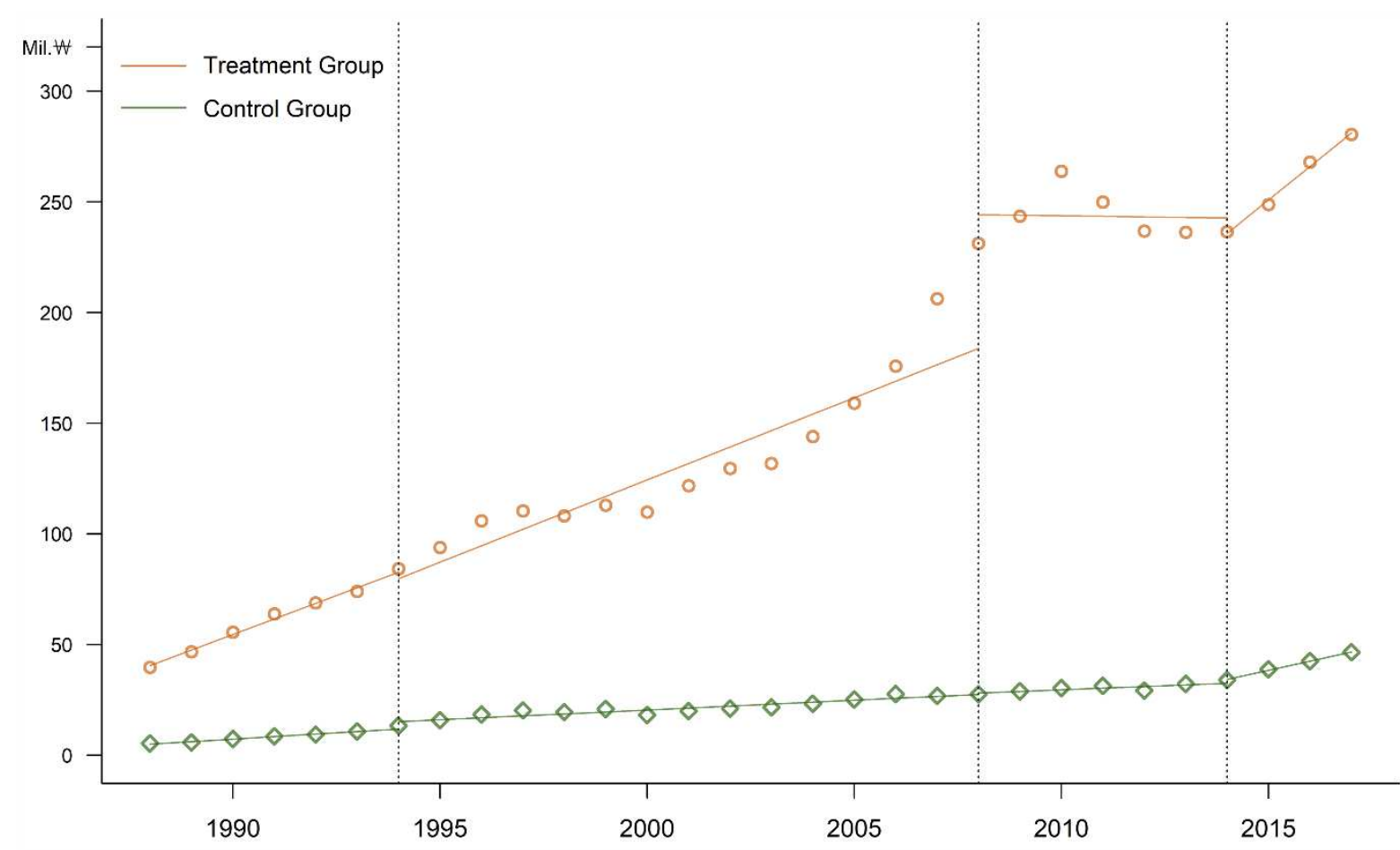

Fig. 5 The results of ITS analysis of the GMP policy

293

Group 1, which preemptively prepared for GMP, had a beginning average production amount that was significantly greater than that of Group 2, which did not prepare in advance $\left(\mathrm{p}=0.0063\right.$ for $\left.\beta_{8}\right)$. Before Policy 1, the GMP mandate implemented in 1994, the level and slope of the treatment group were significantly different $\left(\mathrm{p}=0.0063\right.$ for $\beta_{8}, \mathrm{p}=0.031$ for $\left.\beta_{9}\right)$ than those of the control group. The average production amount was significantly greater immediately after the implementation of Policy 2, which was expanded to include preapproved GMP evaluation of manufacturing items in $2008\left(\mathrm{p}<0.0001\right.$ for $\left.\beta_{12}\right)$. 


\begin{tabular}{cccccc}
\hline \multirow{2}{*}{ Variable } & & Coefficient & S.E. & $\boldsymbol{t}$ & $\boldsymbol{p}$ \\
& $\beta_{0}$ & $3,921,915$ & $7,296,197$ & 0.54 & 0.5936 \\
& $\beta_{1}$ & $1,121,879$ & $1,873,490$ & 0.6 & 0.5524 \\
& $\beta_{2}$ & $3,613,799$ & $7,193,712$ & 0.5 & 0.6179 \\
Contol group & $\beta_{3}$ & $-241,415$ & $1,944,213$ & -0.12 & 0.9017 \\
& $\beta_{4}$ & 769,559 & $8,308,389$ & 0.09 & 0.9266 \\
& $\beta_{5}$ & $-148,447$ & $1,944,213$ & -0.08 & 0.9395 \\
& $\beta_{6}$ & $-1,645,401$ & $11,149,497$ & -0.15 & 0.8834 \\
& $\beta_{7}$ & $3,412,147$ & $3,974,273$ & 0.86 & 0.3952 \\
\hline \multirow{6}{*}{ Treatment group } & $\beta_{8}$ & $29,594,918$ & $10,318,380$ & 2.87 & $0.0063^{*}$ \\
& $\beta_{9}$ & $5,905,425$ & $2,649,515$ & 2.23 & $0.031^{*}$ \\
& $\beta_{10}$ & $-6,906,227$ & $10,173,446$ & -0.68 & 0.5008 \\
& $\beta_{11}$ & 644,845 & $2,749,532$ & 0.23 & 0.8157 \\
& $\beta_{12}$ & $67,319,195$ & $11,749,837$ & 5.73 & $<.0001^{*}$ \\
& $\beta_{13}$ & $-7,534,099$ & $2,749,532$ & -2.74 & $0.0088^{*}$ \\
& $\beta_{14}$ & $-20,685,531$ & $15,767,771$ & -1.31 & 0.1964 \\
& $\beta_{15}$ & $11,963,845$ & $5,620,471$ & 2.13 & $0.0389^{*}$ \\
\hline
\end{tabular}

Table 5 The results of ITS analysis of the GMP policy

After the implementation of Policy 2, there was a significant difference $(p=0.0088$ for $\beta_{13}$ ) between the treatment group and the control group in the slope change (Table 5). Even after the implementation of Policy 3 (2014 PIC/s GMP), the difference in slope between the treatment group and the control group from the previous period was significant $(\mathrm{p}=0.0389$ for $\left.\beta_{15}\right)$.

In conclusion, companies that responded to the GMP system in advance showed excellent pharmaceutical production performance. The treatment group's growth trend also improved more rapidly after the implementation of Policies 2 and 3. After implementing

312 Policy 1, the growth trend did not change significantly because it was sufficiently large in the treatment group before Policy 1 implementation. Nevertheless, there was a significant 
difference in temporary growth level immediately after implementing Policy 2 because the production of 3 batches before drug approval was done for compulsory validation.

\section{Research Question 3: Did the DERP delay the introduction of new drugs in Korea?}

The DERP, which is considered one of the most significant changes to the domestic insurance drug pricing system over the past 30 years, was amended on Dec 29, 2006. This study investigated the impact of the DERP on new drug development using ITS analysis of the change in the new drug's starting date of insurance coverage. The intervention time for the ITS analysis of the DERP was set to January 2007 because the regulatory implementation date was the end of December 2006. According to the health insurance application date, the number of new drugs included in this analysis was 321 before 2007 and 297 from January 2007 until December 2017. The average duration of insurance coverage of the 618 items in the entire period was 19.9 months; it was 18.0 months from 1989 to 2006 and 22.0 months after 2007.

The start of health insurance coverage for new drugs was delayed by about four months after implementing the DERP system. The average periods from approval of the health insurance start day of each year were analyzed using the final ITS model, as shown in Fig. 6. The results of ITS analysis showed that $\beta_{0}=16.8413, \beta_{1}=-0.0242, \beta_{2}=1.3867$, and $\beta_{3}$ $=0.8236$, as shown in Table 6 , and the p-values for $\beta_{1}, \beta_{2}$, and $\beta_{3}$ were all not statistically significant. Note that, although 22.0 months, the average registration time after DERP implementation, is longer than 18.0 months, the average registration time before the DERP policy, the ITS analysis showed no statistical evidence that DERP has resulted in a delay in bringing new drugs to market. It is likely that the several outlier years, such as 1989, 2009, and 2015, make the variance too large for the statistical test to be significant. 


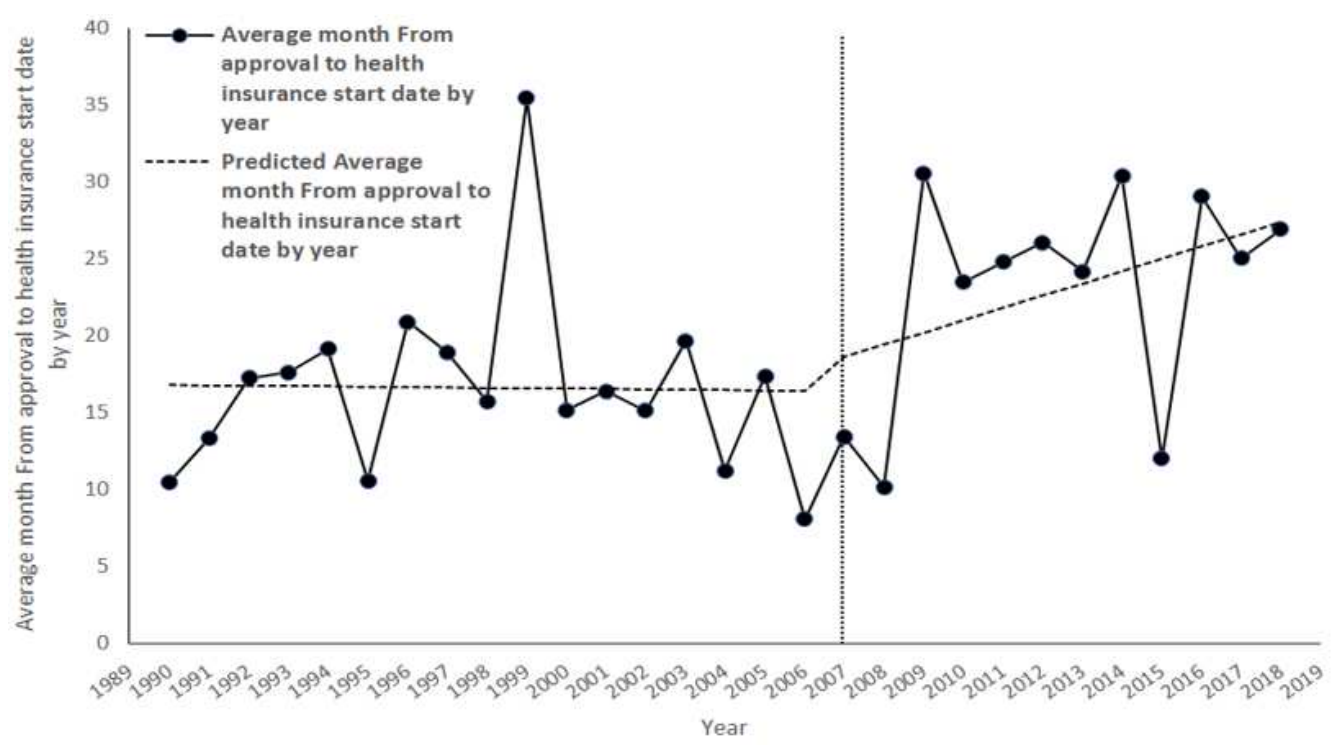

Fig. 6 Average periods from drug approval to health insurance start date

\begin{tabular}{lccc}
\hline \multicolumn{1}{c}{ Variable } & Coefficient & S.E. & p-value \\
\hline Intercept $\beta_{0}$ & 16.8413 & 3.0568 & $<.0001$ \\
Baseline trend $\beta_{1}$ & -0.0242 & 0.2983 & 0.9354 \\
Level change after policy $\beta_{2}$ & 1.3867 & 4.6459 & 0.7653 \\
Trend change after policy $\beta_{3}$ & 0.8236 & 0.5856 & 0.1596
\end{tabular}

Table 6 Average number of months from drug approval to health insurance start date

Although there was a tendency towards an increase in the time between the date of approval of a new drug and the starting date of health insurance coverage, the variation in the average amount of elapsed time was considerable, so the results were not statistically significant. The results differed from our expectations. However, we made the following discoveries when we analyzed the data in detail. If a pharmaceutical company accepts a lower 
price through negotiation with the regulatory authority, the listing period will be shortened.

348 Therefore, the listing period varies depending on the drug company's strategy and the product's cost structure. We also consider that the linkage system between drug approval and price evaluation, which was implemented in 2014 to improve new drug accessibility and supply new drugs to patients quickly, maybe one reason for the lack of statistical significance of the ITS analysis. According to the Health Insurance Review \& Assessment Service, the drug approval and reimbursement registration period of new drugs was shortened to about 100 days immediately after implementing the linkage system between drug approval and price evaluation [36].

\section{Conclusion}

We have investigated the effects of three crucial policies from a long-term (30-year) perspective using a single methodology, ITS analysis. This study is the first long-term study on the impact of significant regulations on the Korean pharmaceutical industry to the best of our knowledge. This study compared the outcomes before and after implementing major product patent system, 30 years to implement the GMP system, and 30 years to change in the pricing system.

Since the introduction of the product patent system, the number of Korean patent applications filed by domestic companies has significantly increased. Many people were worried that foreign companies' strong competitiveness in patent rights would allow them to dominate domestic companies when the product patent system was introduced in 1987 [30]. However, this study shows that domestic companies achieved high growth by developing new drugs, as evidenced by the expanding number of patent applications. This finding 
implies that the product patent policy has reinforced the innovative capabilities of domestic pharmaceutical companies in Korea.

Given the mandatory GMP system changes, pharmaceutical companies need to invest heavily in GMP facilities, and only financially sound companies were able to invest in response to the change. This study showed that the growth of preemptively invested companies was considerable in Korea. This result implies that the pharmaceutical companies should invest in preparation for institutional changes such as GMP.

Unlike previous studies, which claimed that the price regulation system delayed the registration period for new drugs, this study found no significant delay in new drugs until ten years after implementing the DERP system in Korea. This study indicated that Korea compensated for the possible delay of new drugs due to DERP with other policies, such as the linkage system between drug approval and price evaluation, and through negotiations between the companies and the regulatory authorities [29]. Pharmaceutical companies are sensitive to delays in the launch of new drugs since the patent and marketing efforts for the new drug continue to operate regardless of whether the product is on the market. A delay in launching new drugs may be costly to consumers if the drug is more cost-effective than other available options on the current market [11]. This study suggests that national regulatory authorities should supplement drug pricing policies to help pharmaceutical companies with this issue.

The average yearly growth rate of pharmaceutical products in Korea from 1988 to 2017 was $7.59 \%$, greater than $5.26 \%$, which is the Korean GDP growth rate [37]. Korea was one of the world's fastest GDP growth countries in that period. This study showed that Korean pharmaceutical companies actively responded to necessary regulatory policies that guided 
394 and regulated the Korean pharmaceutical industry's significant growth over the past 30 years.

395 To create new drugs that are safe and effective, the Korean government proposed and 396 implemented policies to tighten and strengthen regulations. This study implies that the 397 pharmaceutical industry's fast growth in Korea was possible because the regulatory 398 authorities not only protected consumer health and alleviated cost burdens but also promoted 399 pharmaceutical innovation and improved domestic pharmaceutical companies' 400 competitiveness.

401

402 
1. Schuhmacher A, Gassmann O, Hinder M: Changing R\&D models in researchbased pharmaceutical companies. $J$ Transl Med 2016, 14:105.

2. Carlson R: Estimating the biotech sector's contribution to the U.S. economy. Nature Biotechnology 2016, 34:247-255.

3. DiMasi JA, Feldman L, Seckler A, Wilson A: Trends in Risks Associated With New Drug Development: Success Rates for Investigational Drugs. Clinical Pharmacology \& Therapeutics 2010, 87:272-277.

4. $\quad$ Lipsky MS, Sharp L.K.: From idea to market: the drug approval process. $J \mathrm{Am}$ Board Fam Pract 2001, 14:362-367.

5. Wouters OJ, McKee M, Luyten J: Estimated Research and Development Investment Needed to Bring a New Medicine to Market, 2009-2018. Jama-Journal of the American Medical Association 2020, 323:844-853.

6. Eichler H-G, Hurts H, Broich K, Rasi G: Drug Regulation and Pricing - Can Regulators Influence Affordability? New England Journal of Medicine 2016, 374:1807-1809.

7. Thomas LG: Regulation and firm size: FDA impacts on innovation. Rand Journal of Economics 1990, 21:497-517.

8. Lee PR, Herzstein J: International Drug Regulation. Annual Review of Public Health 1986, 7:217-235.

9. $\quad$ Seiter A: A practical approach to pharmaceutical policy. World Bank Publications; 2010.

10. Artz KW, Norman PM, Hatfield DE, Cardinal L.B.: A Longitudinal Study of the Impact of R\&D, Patents, and Product Innovation on Firm Performance. Journal of Product Innovation Management 2010, 27:725-740.

11. Danzon PM, Wang YR, Wang L: The impact of price regulation on the launch delay of new drugs - evidence from twenty-five major markets in the 1990s. Health Economics 2005, 14:269-292.

12. Immel BK: A brief history of the GMPs for pharmaceuticals. Pharmaceutical technology 2001, 25:44-53.

13. Sood N, de Vries H, Gutierrez I, Lakdawalla DN, Goldman DP: The Effect Of Regulation On Pharmaceutical Revenues: Experience In Nineteen Countries. Health Affairs 2009, 28:W125-W137.

14. Vernon JA: Examining the link between price regulation and pharmaceutical R\&D investment. Health Economics 2005, 14:1-16.

15. Lanjouw JO: Patents, price controls, and access to new drugs: how policy affects global market entry. National Bureau of Economic Research; 2005.

16. Paine MF: Therapeutic Disasters That Hastened Safety Testing of New Drugs. Clinical Pharmacology \& Therapeutics 2017, 101:430-434.

17. Patel KT, Chotai NP: Pharmaceutical GMP: past, present, and future - a review. Pharmazie 2008, 63:251-255.

18. Comanor WS: Research and competitive product differentiation in the pharmaceutical industry in the United States. Economica 1964, 31:372-384.

19. Grabowski HG, DiMasi JA, Long G: The Roles Of Patents And Research And Development Incentives In Biopharmaceutical Innovation. Health Affairs 2015, 34:302-310. 
20. Wagner S, Wakeman S: What do patent-based measures tell us about product commercialization? Evidence from the pharmaceutical industry. Research Policy 2016, 45:1091-1102.

21. Seul MS: Influences of Patent and Drug Safety Regulation Agency and Korea's Direction in Pharmaceutical Industry's Innovation - Focusing on Features of Korea's Pharmaceutical Industry and Biologics. The Journal of Intellectual Property 2016, 11:75-114.

22. Jeong C-H: Changes in Korean Patent System: History of Strengthening Patent Rights. Science and technology policy 2004, 14:79-107.

23. Lee SW: Recent patent trends of Korean pharmaceutical companies. Trends in Health Industry \& Technology 2002, 9:85-91.

24. Yoon KA: Current status of patents in the pharmaceutical industry. Trends in Health Industry \& Technology 2004, 20:75-91.

25. Paik W-H: The History of Korean GMP. Yakhak Hoeji 2015, 59:40-46.

26. Kim JY, Kwon K: A Study on the Comparison of Korea GMP with PIC/S GMP for Enhancing International Competecy of Medicinal Product Quality. Yakhak Hoeji 2013, 57:432-441.

27. DiMasi JA, Hansen RW, Grabowski HG: The price of innovation: new estimates of drug development costs. Journal of Health Economics 2003, 22:151-185.

28. Yang BM, Bae EY, Kim J: Economic evaluation and pharmaceutical reimbursement reform in South Korea's National Health Insurance. Health Affairs 2008, 27:179-187.

29. Son KB: Understanding the adoption of new drugs decided by several stakeholders in the South Korean market: a nonparametric event history analysis. Health Economics Review 2018, 8:10.

30. KPMA: The history of KPMA's 50 years. Korea Pharmaceutical Manufacturers Association; 1996.

31. Bernal JL, Cummins S, Gasparrini A: Interrupted time series regression for the evaluation of public health interventions: a tutorial. International Journal of Epidemiology 2017, 46:348-355.

32. Ewusie JE, Soobiah C, Blondal E, Beyene J, Thabane L, Hamid JS: Methods, Applications and Challenges in the Analysis of Interrupted Time Series Data: A Scoping Review. Journal of Multidisciplinary Healthcare 2020, 13:411-423.

33. Penfold RB, Zhang F: Use of Interrupted Time Series Analysis in Evaluating Health Care Quality Improvements. Academic Pediatrics 2013, 13:S38-S44.

34. Wagner AK, Soumerai SB, Zhang F, Ross-Degnan D: Segmented regression analysis of interrupted time series studies in medication use research. Journal of Clinical Pharmacy and Therapeutics 2002, 27:299-309.

35. Linden A: A comprehensive set of postestimation measures to enrich interrupted time-series analysis. Stata Journal 2017, 17:73-88.

36. Health Insurance Review \& Assessment Service: Press release: Reduced the actual time required for new insurance registration of anticancer drugs from 320 days to 240 days.

[https://www.hira.or.kr/bbsDummy.do?pgmid=HIRAA020041000100\&brdScnBltNo= 4\&brdBltNo=9198] Accessed Feb 222021.

37. Um SI: The empirical study on patterns and factors of growth of Korean 
pharmaceutical industry in recent 30 years. Chung-Ang University, 2019. 
Figures

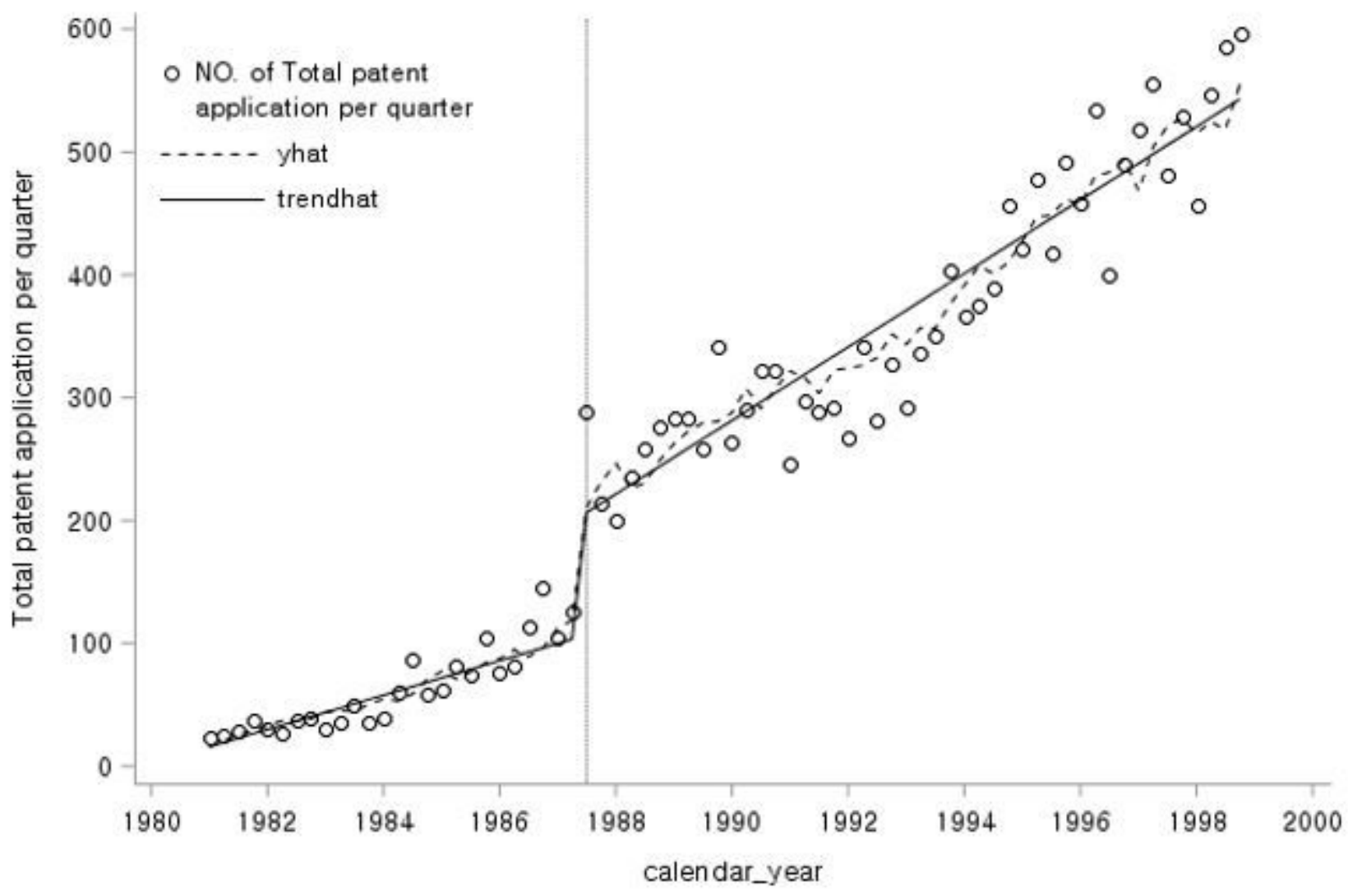

Figure 1

The graphical results of ITS analysis of the total number of patent applications 


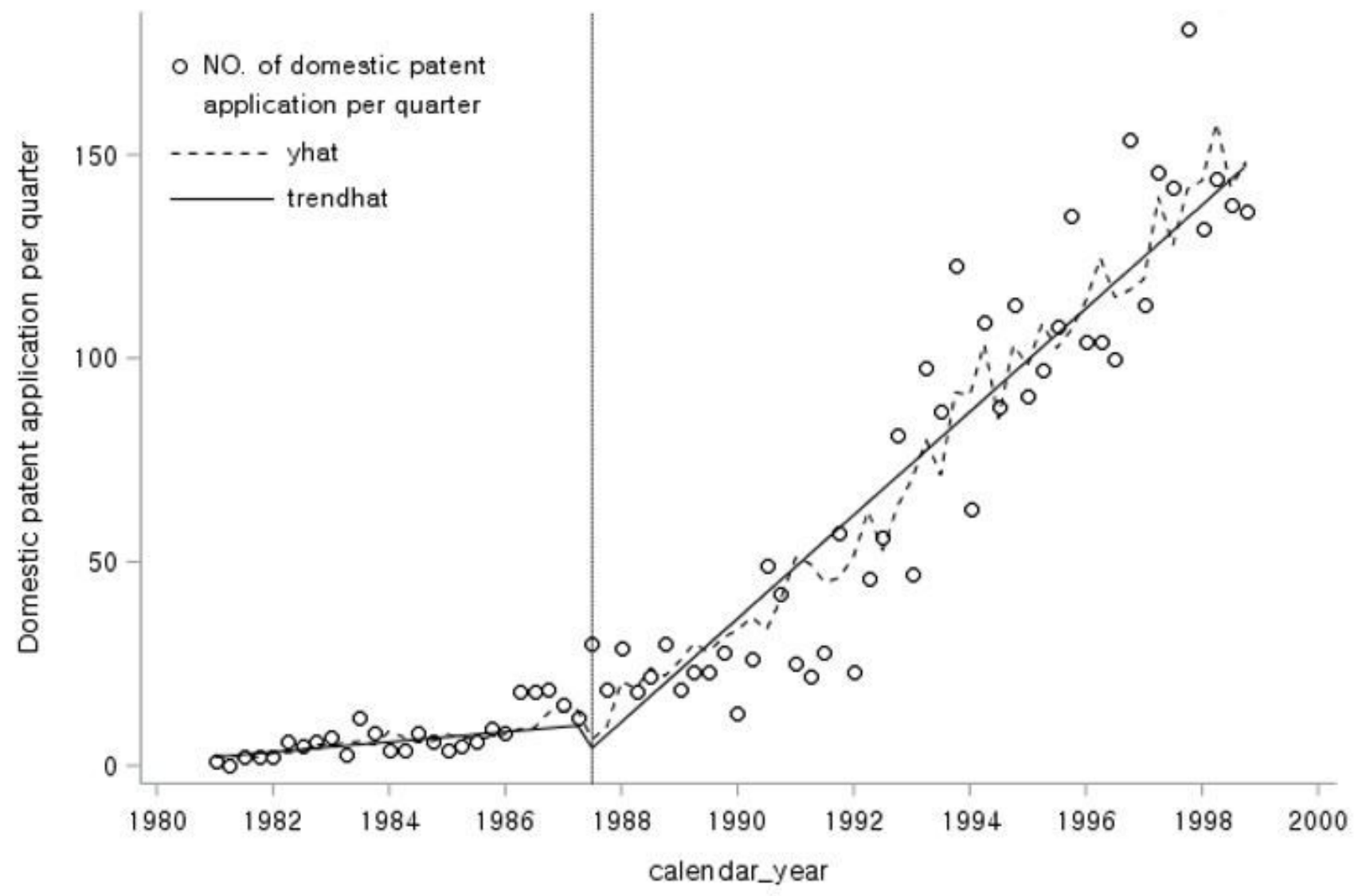

Figure 2

The graphical results of ITS analysis on the total number of Korean patent applications 


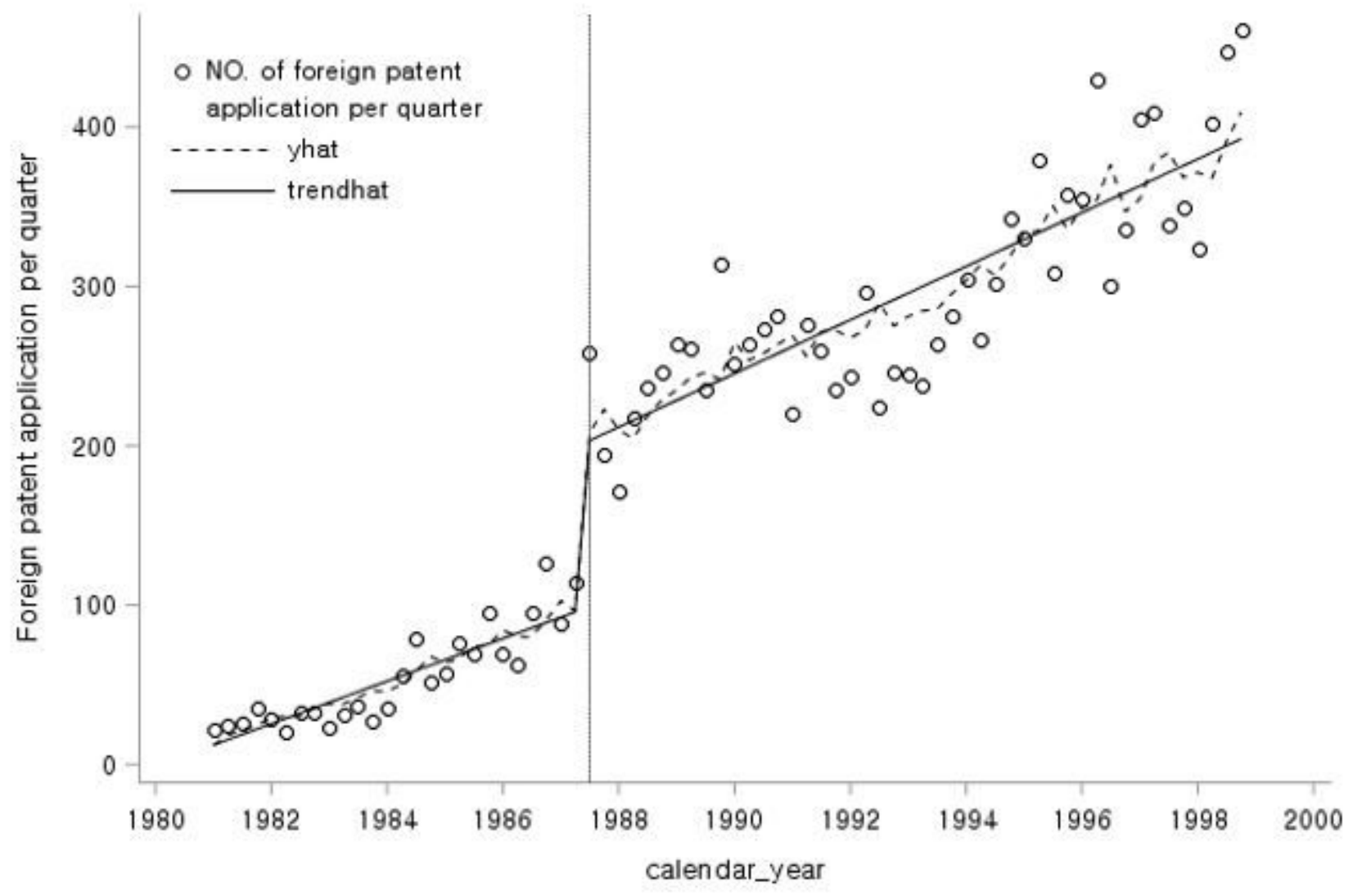

Figure 3

The graphical results of ITS analysis on the total number of foreign patent applications 


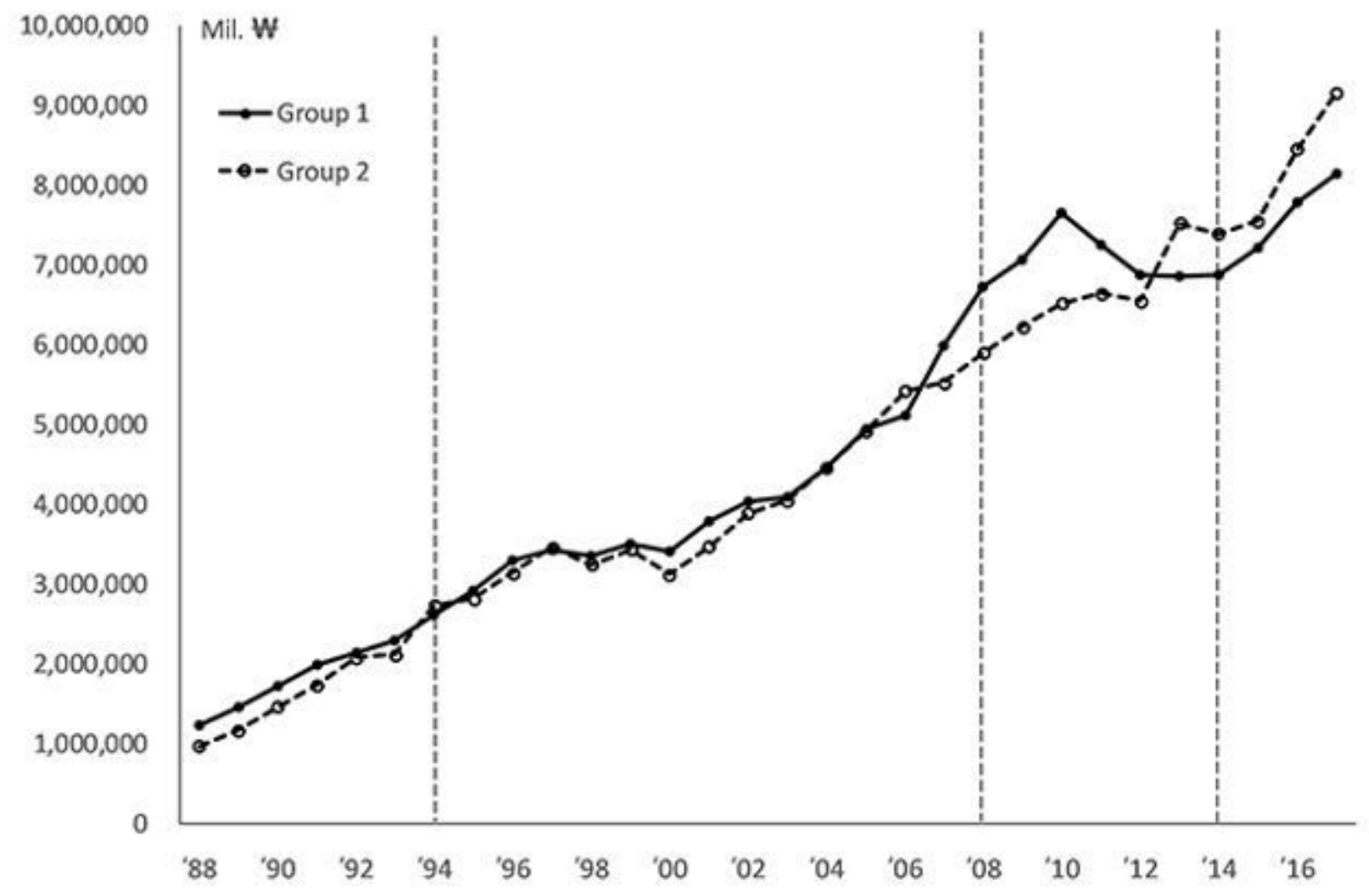

Figure 4

Total production by Group 1 and Group 2 companies over time 


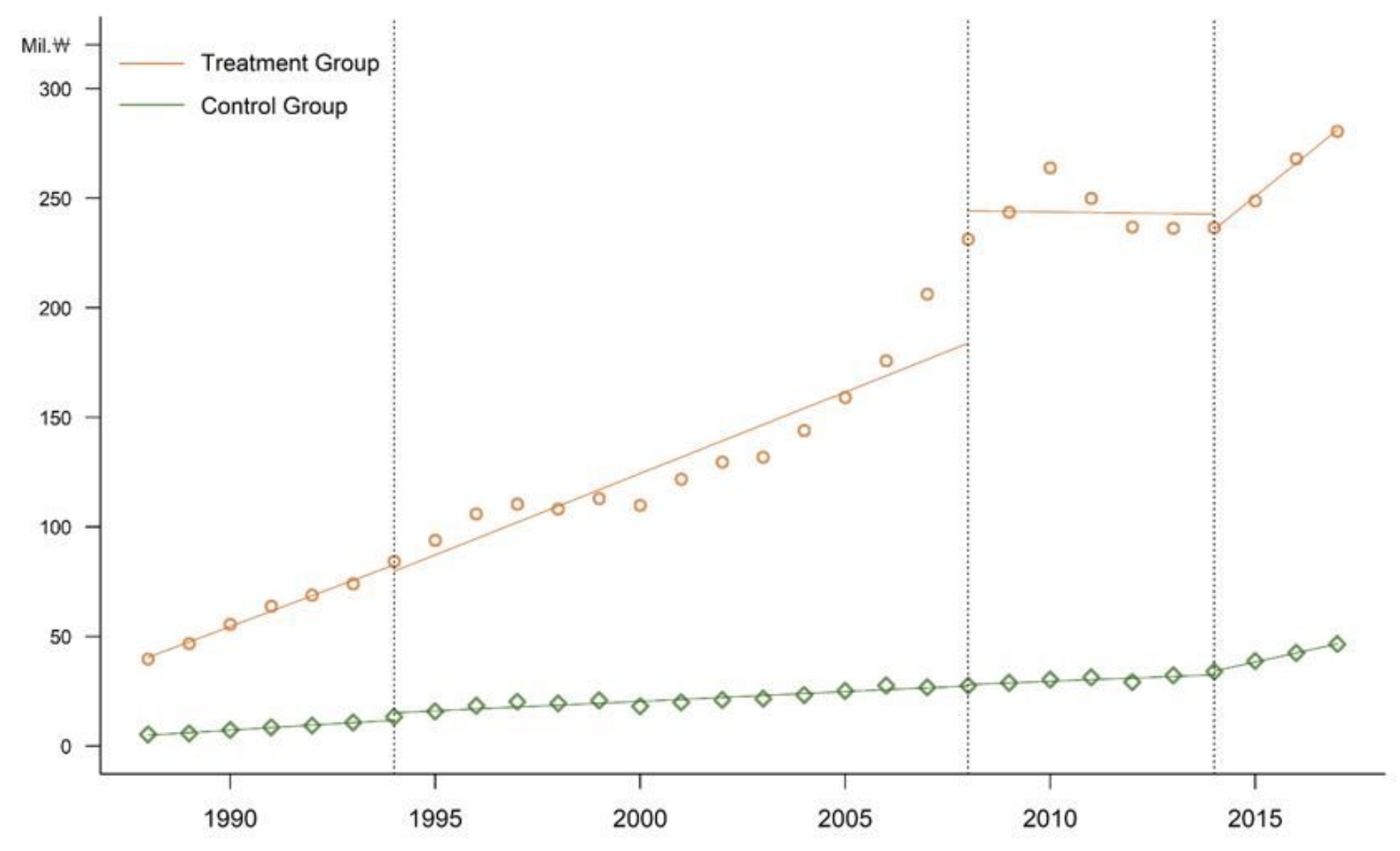

Figure 5

The results of ITS analysis of the GMP policy 


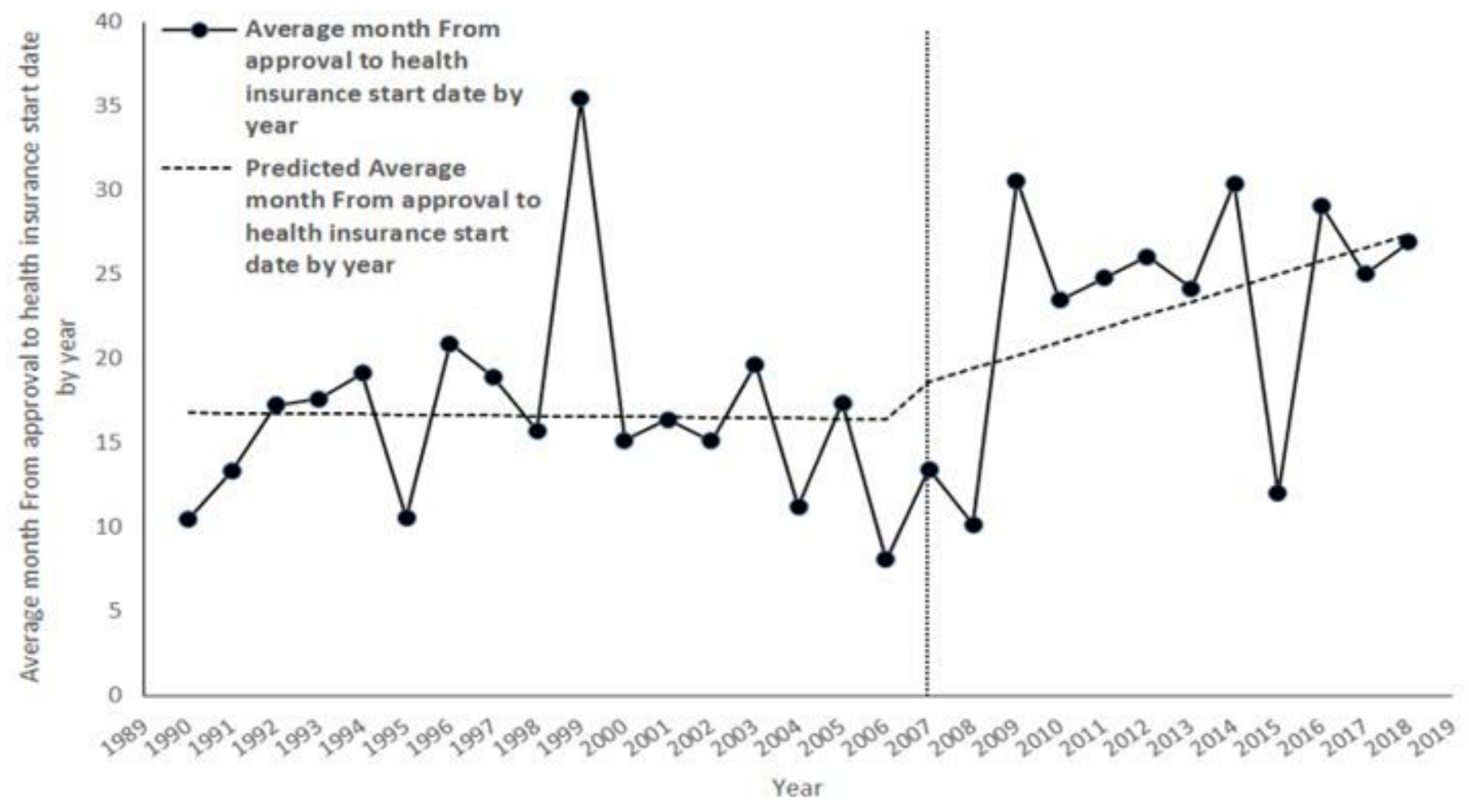

Figure 6

Average periods from drug approval to health insurance start date 